\title{
ISOMETRIAS E GEOGEBRA: O PAPEL DO ARRASTAR NA CONSTRUÇÃO DE CONCEITOS
}

\author{
Marlei Tais Dickel - PPGEMat/UFRGS - ninadickel@ hotmail.com \\ Márcia Rodrigues Notare - PPGEMat/UFRGS - marcia.notare@ gmail.com
}

Resumo: Neste trabalho discute-se o potencial dos ambientes de geometria dinâmica para a construção de conceitos de isometrias. Debate-se o papel da ação de arrastar na manipulação de atividades dinâmicas sobre isometrias com a utilização do GeoGebra. De caráter qualitativo, neste estudo são analisadas atividades matemáticas resolvidas por alunos do $3^{\circ}$ ano do Ensino Médio, da Rede Pública, com base na Teoria das Tecnologias Cognitivas e nas análises cognitivas do arrastar. Os resultados apontam para a compreensão inicial de conceitos que envolvem as isometrias, que surgem a partir da manipulação no software, em forma de arrastamento, conduzindo à construção de pensamentos matemáticos em conjunto com a tecnologia.

Palavras-chave: Isometrias, GeoGebra, Tecnologias Cognitivas, Geometria Dinâmica.

\begin{abstract}
This paper discusses the potential of dynamic geometry environments for the construction of isometry concepts. We discuss the role of the drag action in the manipulation of dynamic isometry activities using GeoGebra. Of qualitative character, in this study are analyzed mathematical activities solved by students of the 3rd year of High School, of the Public Network, based on the Theory of Cognitive Technologies and in the cognitive analyzes of the drag. The results point to the initial understanding of concepts that involve the isometries, which arise from manipulation in software, in the form of movement of dragging, leading to the construction of mathematical thoughts in conjunction with technology.
\end{abstract}

Keywords: Isometries, GeoGebra, Cognitive Technologies, Dynamic Geometry.

\section{Introdução}

Há tempos a geometria faz parte do nosso cotidiano, desde os tempos mais antigos, através de uma quantidade variada de formas geométricas fornecidas pela natureza, bem como em seus desenhos representativos do meio em que viviam. De modo admirável, o homem primitivo foi capaz de transformar a percepção sobre o espaço a sua volta em uma espécie de geometria rudimentar básica, que ele utilizou para construir moradias, tecer, confeccionar vasos e potes, para fazer pinturas e ornamentos.

Da mesma forma, as transformações geométricas fazem parte desta história da humanidade, há mais tempo do que se possa imaginar. Uma das primeiras evidências aparece na pintura rupestre do sítio de El Buey na Bolívia. Em particular, as isometrias têm sido usadas pelo homem como elementos decorativos, no qual as figuras geométricas adquiriram disposições mais complexas, partindo de uma única figura, para construir rosáceas, frisos ou pavimentações (Bacalhau, 2012).

Por outro lado, para Basso e Notare (2015), o surgimento das tecnologias e dos ambientes dinâmicos proporcionou a evolução tanto da Matemática, quanto da Educação Matemática. Nesse cenário o aluno tem a possibilidade de desenvolver a capacidade de pensar em conjunto com a tecnologia. Isto está corroborado com a Base Nacional Comum Curricular (2017), que orienta que a aprendizagem em Matemática está intrinsecamente relacionada à compreensão, ou seja, à apreensão de significados dos objetos matemáticos, sem deixar de lado suas aplicações. Os significados desses objetos resultam das conexões que os alunos estabelecem entre eles e os demais componentes, entre eles e seu cotidiano 


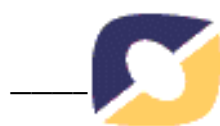

e entre os diferentes temas matemáticos. Desse modo, recursos didáticos como malhas quadriculadas, ábacos, jogos, livros, vídeos, calculadoras, planilhas eletrônicas e softwares de geometria dinâmica têm um papel essencial para a compreensão e utilização das noções matemáticas.

Nestes contextos, no presente trabalho pretende-se aliar estas tendências, discutindo o uso de ambiente de geometria dinâmica inserido em uma proposta matemática sobre isometrias. Em particular, foram desenvolvidas atividades de investigação e manipulação com o uso do software GeoGebra que abordam tais transformações geométricas, sob o embasamento teórico das tecnologias cognitivas e das análises cognitivas do arrastamento.

Na sequência do artigo, apresentamos a fundamentação teórica do trabalho e duas atividades acompanhadas de análises de seu potencial de uso para desencadear novas formas de pensar em matemática.

\title{
2 Aprendizagem de Geometria e as Tecnologias Digitais
}

No que se refere ao uso dos recursos computacionais, em particular os softwares de geometria dinâmica, na Educação Matemática, o pesquisador Giraldo (2012) entende que:

\begin{abstract}
[...] A respeito da integração de recursos computacionais na sala de aula de Matemática, temos como meta uma incorporação efetiva à prática docente sem que o computador se reduza a um mero adereço, alegórico para a abordagem, e que a aula no laboratório de informática adquira um caráter de curiosidade, desconectada da aula "de verdade", aquela com quadro negro e giz. (Giraldo, 2012, p.7).
\end{abstract}

Vale ressaltar que utilizar os recursos computacionais por si só não garante o fazer matemático do aluno. Os professores devem ser críticos e cuidadosos para que tal recurso não se torne algo somente atrativo e que simplesmente reforça as mesmas características do modelo de escola que privilegia a transmissão do conhecimento, e sim apresentar problemas e situações nos quais os alunos possam desenvolver junto à tecnologia o pensamento matemático, o que nos remete a Teoria das Tecnologias Cognitivas.

A Teoria das Tecnologias Cognitivas descreve coletivamente uma ecologia cognitiva em que o pensamento emerge da interação entre pessoas e tecnologias, ou seja, os poderes mentais do aprendiz aceleraram e ampliam, tornando o processo de aprendizagem mais eficiente (Shaffer e Clinton, 2006).

Pea (1987) descreve que uma tecnologia cognitiva é qualquer meio que ajuda a transcender as limitações da mente em pensar, aprender e resolver problemas, ou seja, que os softwares e os computadores, ao serem manipulados e utilizados como ferramentas didáticas, influenciam o pensar dos alunos, assim como os pensamentos matemáticos nem começam nem terminam com o computador, mas surgem no decorrer da exploração, como parte do processo de interação, desenvolvendo pensamentos que vão além das possibilidades obtidas com o lápis e o papel.

Os softwares de geometria dinâmica são um exemplo de tecnologia cognitiva, pois segundo Gravina e Contiero (2011), são aplicativos que têm o recurso de "estabilidade sob ação de movimento", isto é, após uma construção geométrica, pode-se movimentar os objetos geométricos na tela do computador, variando seu tamanho e posição, mas preservando suas propriedades.

Sob estas perspectivas, observamos nas práticas desta pesquisa que os alunos, ao manipularem os objetos nos softwares de geometria dinâmica, expressam por meio desta 
exploração diferentes modalidades de arrastamento, a fim de alcançar objetivos, como explorar, conjecturar, validar conceitos matemáticos, entre outros.

Segundo Arzarello (2002), a utilização da ação de arrastar em ambientes dinâmicos proporciona a elaboração de conjecturas, que conduzem os estudantes à construção de conceitos matemáticos, a fim de desenvolver o pensamento matemático. Segundo o autor, podem ser identificadas sete modalidades de arrastar que auxiliam na compreensão do pensamento matemático, apresentados a seguir:

- Arrastar "sem rumo": move pontos básicos na tela aleatoriamente, sem um plano, a fim de descobrir configurações interessantes ou regularidades nas figuras.

- Arrastar limitado: move um ponto "semi-arrastável" (o ponto apresenta restrições de movimento por ser dependente de outro objeto geométrico na construção).

- Arrastar guiado: arrasta pontos básicos de uma figura, a fim de impor à mesma uma forma particular.

- Arrastar lugar geométrico ou "locus": move um ponto básico para que a figura mantenha uma propriedade descoberta; o ponto que é movido segue um caminho pré-estabelecido, mesmo que os usuários não percebam isto: o locus não é visível e nem sempre evidente para as estudantes, que podem não perceber que estão arrastando o ponto ao longo de um lugar geométrico.

- Arrastar alinhado: desenha novos pontos ao longo de uma linha para manter a regularidade da figura.

- Arrastar vinculado: vincula um ponto a um objeto, movendo-o para esse objeto.

- Arrastar teste: movimenta os pontos arrastáveis ou semi-arrastáveis, a fim de verificar se a figura mantém propriedades iniciais. Se sim, então a figura passa no "teste"; caso contrário, a figura não foi construída de acordo com as propriedades geométricas que a definem.

Segundo Arzarello (2002), as modalidades de arrastar sem rumo e guiada são geralmente utilizadas em fases de exploração e descoberta; a modalidade de arrastar locus está associada à elaboração de uma conjectura; o arrastar teste é usado principalmente para testar uma conjectura. Portanto, analisar como os alunos usam o recurso de arrastar em ambientes de geometria dinâmica pode fornecer informações sobre seus processos cognitivos e o nível de compreensão sobre o problema no qual estão trabalhando.

Assim, é possível verificar que as ações de arrastar descritas acima podem ser utilizadas tanto para explorar e conjecturar propriedades matemáticas, quanto para validar uma conjectura ou prova.

O software escolhido nesta pesquisa foi o GeoGebra, pois permite, dentro da concepção da geometria dinâmica, explorar diferentes representações de um mesmo conceito matemático. Incluem-se como características, a disponibilidade de inúmeros recursos de construção exibidos em barras de comandos.

\section{Transformações geométricas: Isometrias}

Nessa seção, vamos apresentar de forma geral as transformações geométricas, foco desse estudo. Uma transformação geométrica é uma função que faz corresponder a cada objeto geométrico do plano, um novo objeto geométrico desse plano. Estas transformações podem ser observadas em construções, objetos, obras de arte, elementos da natureza, em uma imagem no espelho, em reflexos na água, as quais são definidas por conceitos matemáticos. 
Este artigo, em particular, aborda as transformações geométricas do tipo isometrias. As isometrias são transformações geométricas que preservam distâncias e amplitudes, ou seja, medidas e ângulos da figura transformada são congruentes às medidas e aos ângulos da figura inicial. Segundo Lima (1996), toda isometria T:r $\rightarrow \mathrm{s}$, é uma função bijetiva, sendo uma isometria da reta $r$ na reta $s$ uma função $T: r \rightarrow s$ que preserva a distância entre os pontos. Segundo o autor, toda isometria possui as seguintes propriedades:

- A imagem de uma reta por uma isometria é uma reta;

- Uma isometria preserva o paralelismo;

- Uma isometria preserva ângulos.

As isometrias são compostas por três tipos de transformação: reflexão, rotação e translação. Em uma reflexão, temos uma reta $\mathrm{r}$ como eixo de simetria, que divide a fígura em duas partes que coincidem por sobreposição, no caso da Figura 1, polígono $\mathrm{A}=$ polígono A'. Destaca-se, também que, ao se refletir uma figura em torno de uma reta, todas as distâncias (medidas dos segmentos que compõem a figura) e amplitudes são preservadas, tornando as figuras congruentes, no entanto estas não mantêm a mesma orientação no plano, como nos mostra a Figura 1.

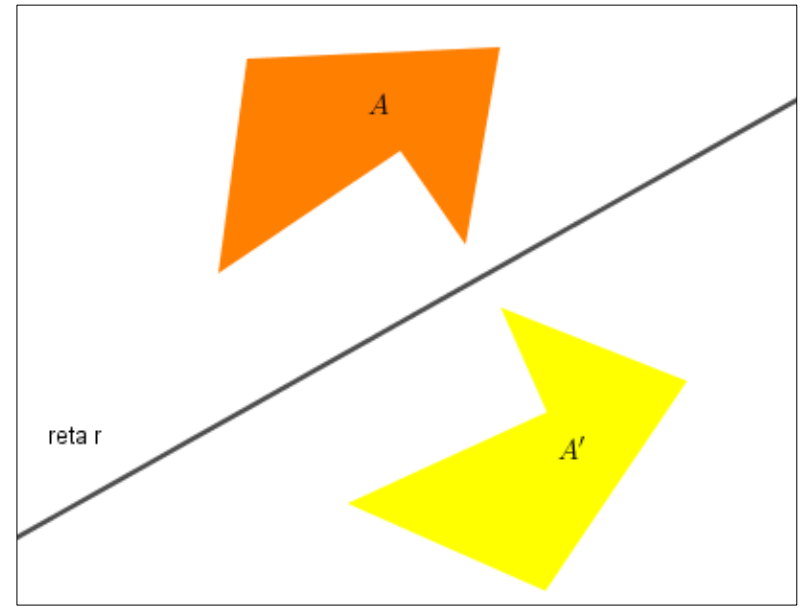

Figura 1: Reflexão de um polígono em torno de uma reta Fonte: Construção feita pelas autoras.

A translação é caracterizada pelo deslocamento de uma distância ao longo de uma direção e de um sentido, ou seja, de um vetor, conforme ilustra a Figura 2.

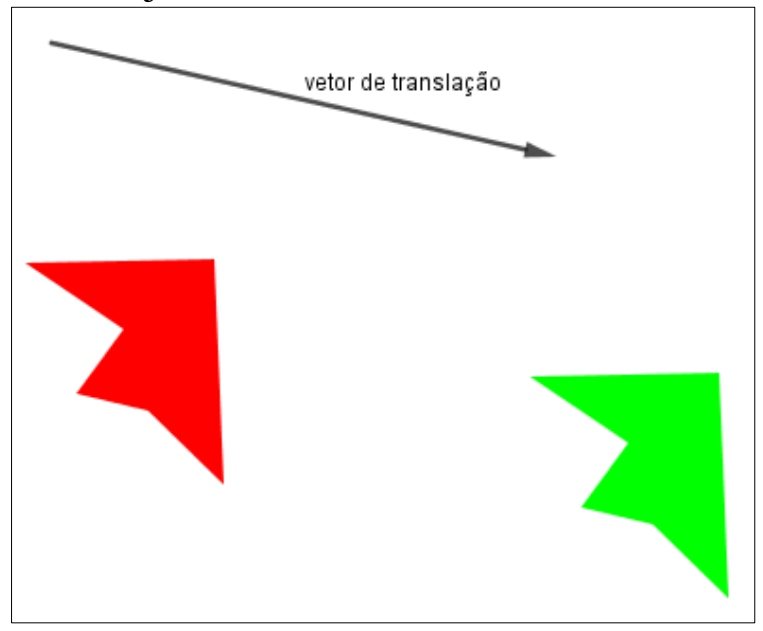

Figura 2: Translação de um polígono por um vetor Fonte: Construção feita pelas autoras. 
A rotação é um movimento circular, segundo um ângulo, que um objeto faz em torno de um ponto, chamado centro de rotação, como mostra a Figura 3.

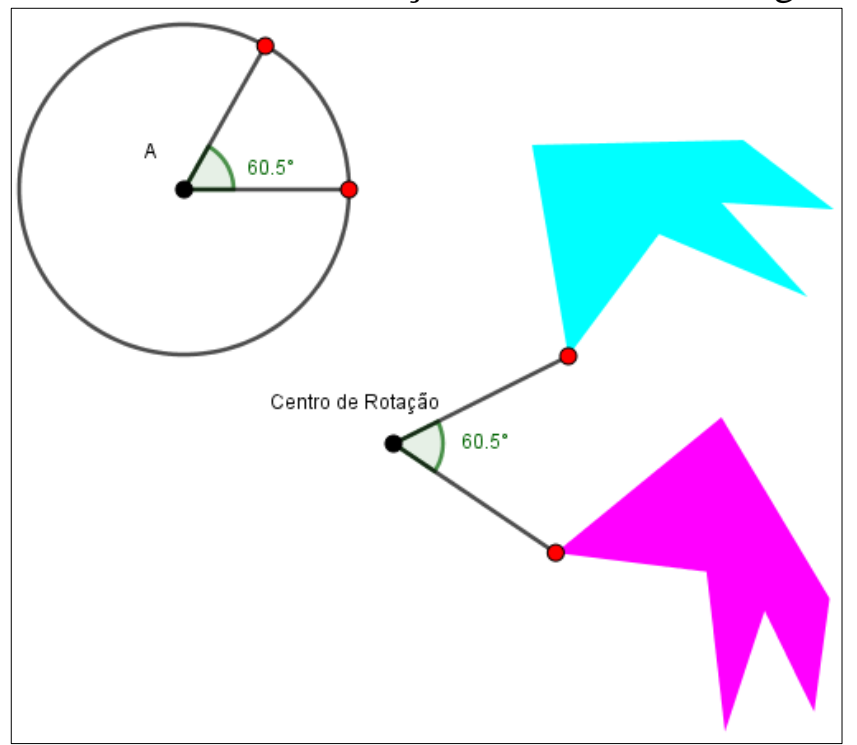

Figura 3: Translação de um polígono por um vetor Fonte: Construção feita pelas autoras

Percebe-se, pelas Figuras 1, 2 e 3, que as isometrias, de fato, preservam medidas e ângulos, mantendo-se congruentes.

A seguir discute-se a compreensão dos conceitos de isometrias a partir da análise da ação de arrastar em atividades com o software GeoGebra.

\section{Isometrias com o GeoGebra: análise de casos}

Nesta seção são apresentadas e discutidas duas atividades realizadas na pesquisa de mestrado da autora, que configuram um recorte de uma sequência de atividades mais ampla que foi elaborada com o objetivo de desenvolver os conceitos de isometrias. A experiência foi realizada em uma turma de terceiro ano do Ensino Médio, em uma escola da Rede Pública, na cidade de Teutônia, Rio Grande do Sul. A turma em que se desenvolveu a pesquisa foi escolhida para o desenvolvimento deste trabalho por já ter estudado o conteúdo de Geometria Plana, bem como, já terem trabalhado com o GeoGebra. A turma contava com vinte e três alunos, de classe média, com acesso a recursos tecnológicos e que gostavam de atividades que envolvessem tecnologia. A experiência foi desenvolvida na sala de aula com a utilização de netbook's.

A coleta de dados se deu por meio de gravações de vídeo das atividades que estavam sendo trabalhadas no GeoGebra, registros escritos feitos pelos alunos, observações da pesquisadora e arquivos do GeoGebra produzidos pelos alunos.

Nas duas atividades ${ }^{1}$ aqui apresentadas, os estudantes, em duplas, deveriam utilizar o software GeoGebra para explorar, por meio do movimento de arrastar, pontos construídos sobre objetos geométricos que provocavam em outros pontos, deles dependentes, as transformações de isometrias. A partir da ação de arrastar, as propriedades geométricas e os elementos que definem cada uma das isometrias poderiam

\footnotetext{
${ }^{1}$ As atividades podem ser acessadas pelos seguintes links: 


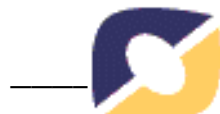

ser observados pelos estudantes. Nas análises, cada atividade está acompanhada pelas conjecturas e respostas apresentadas pelos estudantes. As duas atividades foram selecionadas para ilustrar o potencial do GeoGebra para promover o pensar em matemática, nas quais a tecnologia torna-se um instrumento matemático importante. A característica principal que difere os dois problemas está centrada na ação de arrastar proporcionada pelo GeoGebra.

Na primeira atividade, temos o recurso de arrastar sendo usado pelos alunos para investigar e descobrir propriedades impostas pelo problema, que são mantidas sob ação do movimento. Na segunda atividade, o recurso de arrastar foi usado para explorar e realizar conjecturas, reconhecendo os três tipos de isometrias: reflexão, rotação e translação. Em ambos os casos, a tecnologia revela-se importante no desenvolvimento do pensamento matemático, como um recurso que amplia as capacidades de pensar dos estudantes.

A atividade 1 foi apresentada aos alunos com o seguinte enunciado:

Mova o ponto mova-me e responda os seguintes questionamentos:

1. Ao movimentar o ponto mova-me, o que você observa?

2. Como é possível obter os outros corações "iguais", a partir do ponto movame?

3. Qual a diferença entre os corações construídos?

4. Qual a relação destes corações construídos com o inicial?

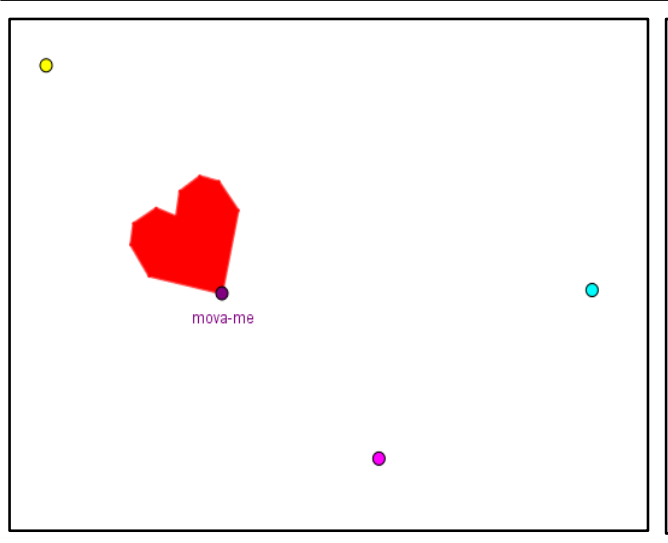

(a)

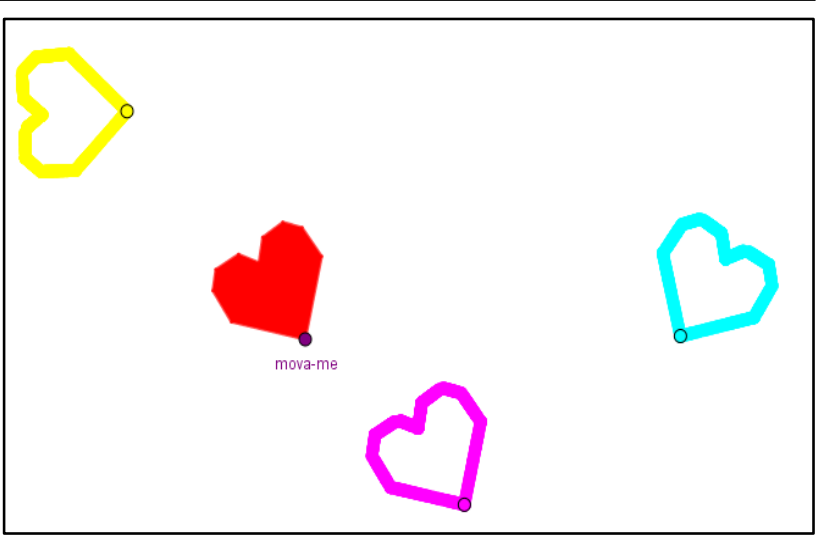

(b)

Figura 4: Tela inicial da atividade 1.

Fonte: Construção feita pelas autoras.

O objetivo desta atividade foi proporcionar um ambiente para descobrir propriedades básicas das isometrias e descrevê-las, por meio da ação de arrastar o ponto principal mova-me, conforme as imagens na Figura 4. Destaca-se que, ao movimentar o ponto mova-me construído sobre o coração vermelho (único ponto com liberdade de movimento nessa atividade), os pontos amarelo, azul e rosa também movimentavam, de forma simultânea, traçando por meio do recurso de rastro os corações nas respectivas cores (Figura 4b).

Os alunos, ao manipular o ponto para solucionar a atividade, apresentaram três comportamentos distintos, no que diz respeito à ação de arrastar. Primeiro, foi possível perceber que suas ações se configuravam como a modalidade de arrastar livre por toda a janela visualização, ou seja, um arrastar sem rumo, segundo a modalidade descrita por Arzarello (2002), na qual a intenção dos estudantes era explorar, para descobrir 


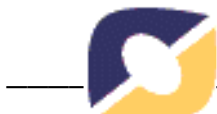

aleatoriamente o que acontecia com os corações, pois além do ponto mova-me, os alunos movimentavam o coração. Para tanto este grupo de alunos, movimentava o ponto de forma a criar os corações em diferentes espaços da tela. Nesse processo, perceberam que o ponto azul fazia o "andar do ponto ao contrário" do ponto mova-me, conjecturando que os corações azul e vermelho estavam "espelhados". A ação de arrastar e observar o que acontece permitiu aos estudantes a realização dessa conjectura. A ação de retirar o coração vermelho do lugar, colocando-o em diferentes posições da tela do computador, permitiu que a conjectura "passasse no teste", ou seja, o coração azul continuava espelhado.

O segundo comportamento observado foi caracterizado por uma dupla de estudantes, que teve a ideia de, além de arrastar o ponto mova-me sem rumo, arrastar testando propriedades a partir de novas construções realizadas por eles que permitiam verificar suas conjecturas. Analisando a construção e observando seus diálogos, percebeu-se que foram construídas circunferências para investigar o que possivelmente estava ocorrendo com os corações. Para esse grupo de alunos, o movimento que estava sendo observado era o de giro (rotação), onde cada ponto girava a partir do principal (na construção deles o ponto vermelho) com ângulos distintos.

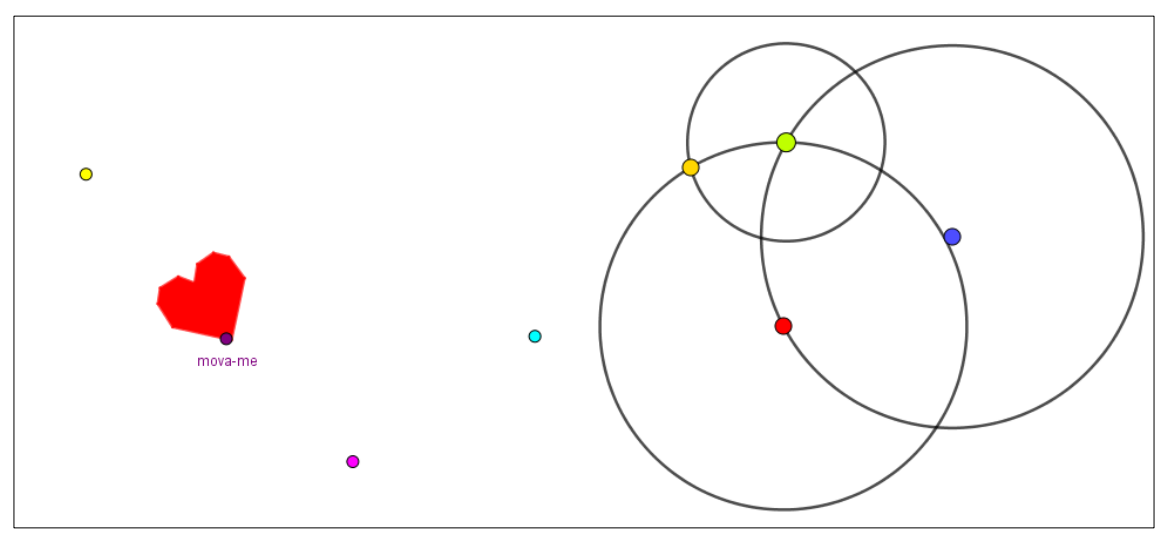

Figura 5: Modelo utilizado pelo grupo de alunos. Fonte: Construção feita pelas alunos.

Neste momento, o grupo utilizou a tecnologia como ferramenta para pensar na situação apresentada e tentar compreendê-la, fazendo uso dos recursos do software para elaborar conjecturas e descobrir o que estava acontecendo com os corações.

O terceiro comportamento observado foi a utilização de recursos do software não propostos pela atividade, indo além do arrastar o ponto mova-me e buscando entender as situações através da janela de álgebra, disponível no programa. Estes alunos utilizaram as abas de propriedades e a janela de álgebra para exibir objetos que estavam ocultos, como o vetor de translação, o ângulo de rotação e a reta de reflexão para auxiliar na compreensão do que estava acontecendo com os pontos que construíam os demais corações. Logo estes alunos já foram fazendo suas conjecturas, indicando quais ferramentas criavam os respectivos corações, por exemplo, o vetor comandava o movimento da construção do coração rosa, apontando assim primitivos das isometrias. 
A atividade 2 foi descrita com o seguinte enunciado:

Mova o ponto mova-me e responda os seguintes questionamentos:

1. Ao movimentar o ponto mova-me, o que você observa?

2. O que você percebe ao movimentar o ponto mova-me em relação a reta?

3. O que você percebe ao movimentar o ponto mova-me em relação ao círculo e ângulo?

4. O que você percebe ao movimentar o ponto mova-me em relação ao vetor?

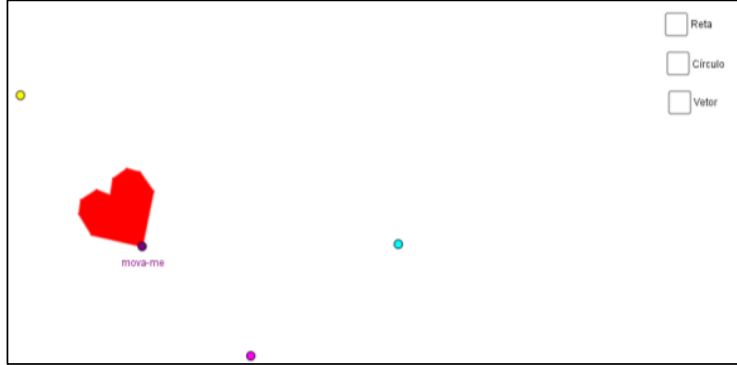

(a)

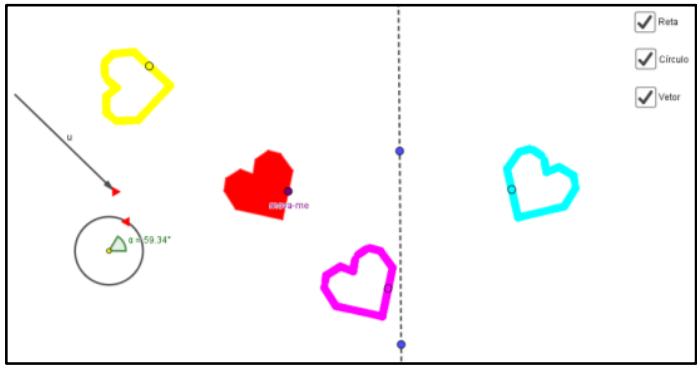

(b)

Figura 6: Tela inicial da atividade 2.

Fonte: Construção feita pelas autoras.

O objetivo desta atividade foi fornecer mais elementos para que os estudantes pudessem explorar, descobrir e descrever as isometrias, por meio do arrastar do ponto principal mova-me, identificando qual elemento geométrico foi utilizado para construir cada um dos corações. Assim, nessa atividade, o estudante teve a possibilidade de colocar em evidência os três elementos principais que definem as isometrias: reta de reflexão, ângulo de rotação e vetor de translação, como ilustra a Figura 6. Destaca-se que os três elementos eram dinâmicos, ou seja, poderiam ser arrastados livremente nesse processo exploratório.

Ao iniciar a exploração da atividade 2, os alunos logo partiram para a utilização das ferramentas reta, vetor e ângulo, arrastando-as pela tela do computador de forma a descobrir qual ferramenta era utilizada no traçado de cada um dos corações, indo ao encontro das modalidades de Arzarello (2002), em particular, o arrastar teste e o arrastar vinculado.

A primeira ferramenta a ser movimentada foi a reta, pois já haviam concluído, na atividade 1, que o coração azul era espelhado, validando suas conjecturas. Nesse caso, a movimentação da reta possibilitou que os alunos validassem uma conjectura que já havia sido elaborada, ou seja, o arrastar da reta de reflexão entrou como teste para a conjectura de que os corações vermelho e azul estavam espelhados (refletidos). O movimento do vetor levou os estudantes a perceberem que o coração rosa também se movimentava de acordo com a direção, comprimento e sentido do vetor. Nesse caso, pela forma como os alunos arrastaram o vetor, verificou-se que ainda não haviam compreendido a transformação de translação, sendo crucial essa etapa de exploração para que a construção dessa ideia tivesse início. O movimento que exigiu mais exploração dos alunos para a compreensão foi o de rotação. Foi necessária a intervenção da pesquisadora para identificar, juntamente com os alunos, o ângulo de rotação, destacando de forma explícita o ângulo entre os corações vermelho e amarelo, como mostra a Figura 7, validando que as medidas dos ângulos apresentados são iguais, isto é, $\alpha=\beta$. Desta forma, a compreensão emerge da interação entre alunos e tecnologia, que amplia as possibilidades de pensar dos alunos, proporcionando, de maneira dinâmica, a observação sobre que está 


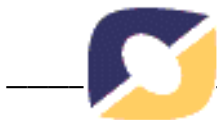

ocorrendo por meio da construção de novos elementos geométricos, que levaram à validação de conjecturas e hipóteses sobre a congruência dos ângulos apresentados, para a compreensão do movimento de rotação.

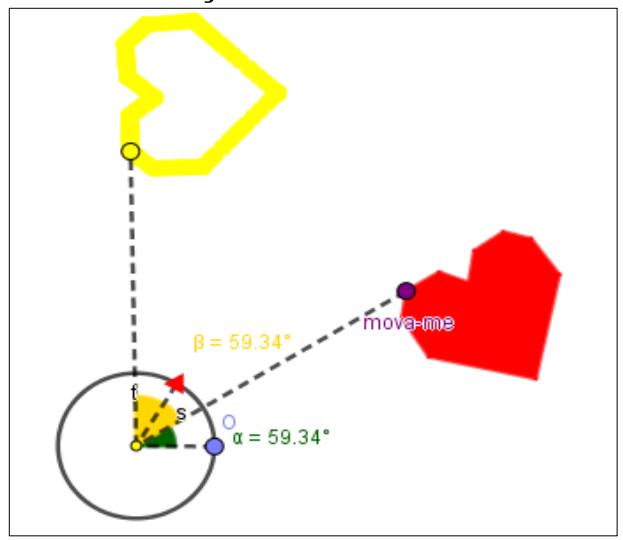

Figura 7: Ângulo de rotação.

Fonte: Construção feita pelas autoras.

Após a oportunidade de exploração em ambiente de geometria dinâmica, os alunos registraram observações sobre os três tipos de movimentos, conforme ilustra Figura 8.
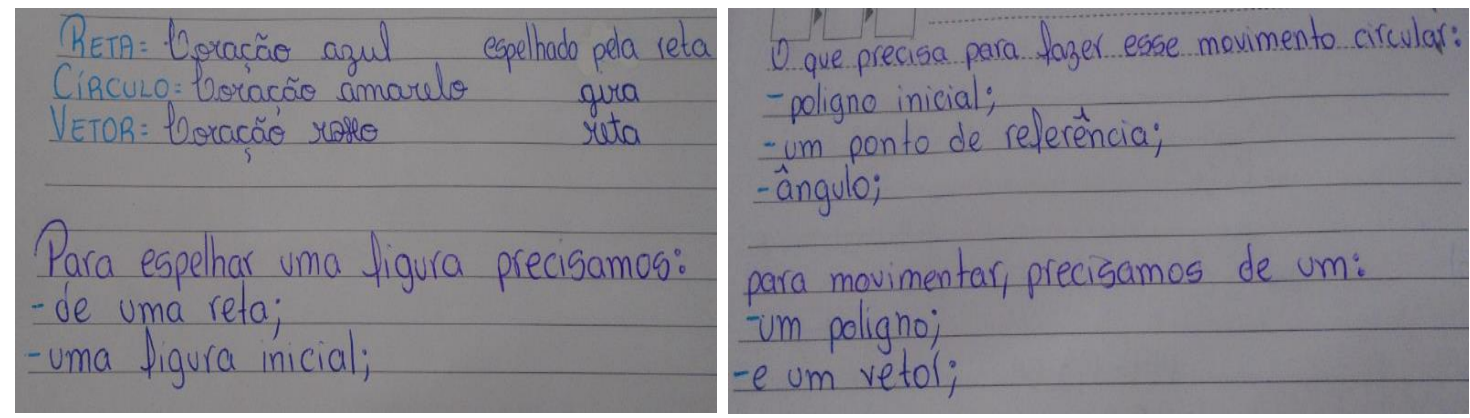

Figura 8: Escrita dos alunos

Fonte: Cópia de caderno de aluno.

$\mathrm{O}$ registro escrito dos alunos quanto aos movimentos indica, de forma ainda embrionária, conceitos-chaves das isometrias, relacionado o movimento espelhado com a reflexão, o movimento circular com a rotação e o movimento livre com a translação, reconhecendo em cada uma das isometrias suas propriedades básicas. Isso revela que os estudantes, a partir da interação com os recursos do GeoGebra, da ação contínua de arrastar para explorar e descobrir, compreenderam a essência das isometrias.

Os resultados obtidos nestas duas atividades apontam uma evolução satisfatória dos alunos na compreensão das isometrias, pois observando os diálogos e respostas, conseguimos identificar uma base conceitual das isometrias apresentadas na forma de linguagem coloquial, como elementos e propriedades fundamentais.

\section{Considerações finais}

Consideramos que os resultados obtidos nestas atividades reforçam a Teoria das Tecnologias Cognitivas, quanto às atitudes dos alunos frente ao processo de aprender: experimentam; criam estratégias; fazem conjeturas; e testam propriedades matemáticas. A partir de manipulação concreta de pontos na tela do computador, que colocam a construção em movimento, os alunos observam, conjecturam e testam, para elaborar 
conceitos e ideias. Em uma etapa seguinte, é possível passar para a manipulação abstrata dos elementos geométricos, atingindo níveis mentais superiores.

Nesse recorte de experiência, observamos a ferramenta tecnológica propiciando uma abordagem experimental da matemática. A partir de experimentos dinâmicos, proporcionados pela ação de arrastar, regularidades vão aparecendo, conduzindo à formação do pensamento matemático.

As atividades descritas neste artigo constituíram a base para uma proposta mais ampla de pesquisa, que visou construir conceitos de isometrias em um ambiente de geometria dinâmica por meio da compreensão e construção de ilusões de óptica.

\section{Referências Bibliográficas}

ARZARELLO, F. A cognitive analysis of dragging practises in Cabri environments. ZDM. Torino, vol. 34, 2002.

BRASIL. Ministério da Educação. Base Nacional Comum Curricular. Brasília: MEC, 2017. Disponível em: < http://portal.mec.gov.br/conselho-nacional-de-educacao/basenacional-comum-curricular-bncc $>$. Acesso em: 1 mai. 2018.

BACALHAU, F. M. Isometrias do plano e Simetria. Universidade de Lisboa, 2012. Dissertação de Mestrado em Matemática para professores.

BASSO, M., NOTARE, M. Pensar-com Tecnologias Digitais de Matemática Dinâmica. Revista Novas Tecnologias na Educação - RENOTE, Porto Alegre: UFRGS, v.13, n.2, 2015 .

GRAVINA, M. A.; CONTIERO, L. O. Modelagem com o GeoGebra: uma possibilidade para a educação interdisciplinar? Revista Novas Tecnologias na Educação - RENOTE, Porto Alegre: UFRGS, v.9, n.1, 2011.

GIRALDO, V. Recursos computacionais no ensino de matemática. Rio de Janeiro: SBM, 2012.

LIMA, E. L. Isometrias. 2a . ed. Rio de Janeiro: Sociedade Brasileira de Matemática (SBM), 2007.

SHAFFER, D. W., CLINTON, K. Toolforthoughts: Reexamining Thinking in the Digital Age. MIND, CULTURE AND ACTIVITY. Regents of the University of California on behalf of the Laboratory of Comparative Hum"n Cognition, 2006.

Disponível em: http://lchc.ucsd.edu/mca/Journal/pdfs/13-4-williamson.pdf . Acesso: 1 mai. 2018.

PEA, R. (1987). Cognitive technologies for mathematics education. In A.H. Schoenfeld (Ed.), Cognitive Science and Mathematics Education (pp. 89-122). Hillsdale: Lawrence Erlbaum. Disponível em: http://web.stanford.edu/ roypea/RoyPDF\%20folder/A41_Pea_87b.pdf. Acesso: 1 mai. 2018. 